\title{
Sealing Ducts in Large Commercial Buildings with Aerosolized Sealant Particles
}

\author{
M. P. Modera, O. Brzozowski ${ }^{*}$, F. R. Carrié ${ }^{\text {* }}$, D. J. Dickerhoff, \\ W. W. Delp, W. J. Fisk, R. Levinson, D. Wang
}

\begin{abstract}
Electricity energy savings potential by eliminating air leakage from ducts in large commercial buildings is on the order of $10 \mathrm{kWh} / \mathrm{m}^{2}$ per year $\left(1 \mathrm{kWh} / \mathrm{ft}^{2}\right)$. We have tested, in two large commercial buildings, a new technology that simultaneously seals duct leaks and measures effective leakage area of ducts. The technology is based upon injecting a fog of aerosolized sealant particles into a pressurized duct system. In brief, this process involves blocking all of the intentional openings in a duct system (e.g., diffusers). Therefore, when the system is pressurized, the only place for the air carrying the aerosol particles to exit the system is through the leaks. The key to the technology is to keep the particles suspended within the airstream until they reach the leaks, and then to have them leave the airstream and deposit on the leak sites. The principal finding from this field study was that the aerosol technology is capable of sealing the leaks in a large commercial building duct system within a reasonable time frame. In the first building, $66 \%$ of the leakage area was sealed within 2.5 hours of injection, and in the second building $86 \%$ of the leakage area was sealed within 5 hours. We also found that the aerosol could be blown through the VAV boxes in the second building without impacting their calibrations or performance. Some remaining questions are (1) how to achieve sealing rates comparable to those experienced in smaller residential systems; and (2) what tightness level these ducts systems can be brought to by means of aerosol sealing.
\end{abstract}

\footnotetext{
** Ecole Nationale Superieure d'arts et Metiers (ENSAM), Paris, France

* On leave from Ecole Nationale des Travaux Publics de l'Etat, Laboratoire des Sciences de l'Habitat, DGCB - URA CNRS 1652, 2 rue Maurice Audin, 69518 Vaulx-en-Velin Cedex, France
} 


\section{Introduction}

Considerable research has been conducted on the leakage levels of various types of ducts and duct fittings (ASHRAE 1997, Swim and Griggs 1995), and the Sheet Metal Contractors National Association (SMACNA) even has a manual on HVAC duct leakage (SMACNA 1985). The SMACNA manual defines the leakage class as a metric to characterize the leakage area of a duct system. It is based on the leakage airflow rate at one inch of water $(250 \mathrm{~Pa})$ normalized by the duct surface area. According to ASHRAE (1997), leakage classes of 3 to $12 \mathrm{cfm} @ 1$ ” $\mathrm{H}_{2} \mathrm{O} / 100 \mathrm{ft}^{2}$ are attainable for "commonly used duct construction and sealing practices" when leakage at connections to grilles, diffusers, and registers is not considered. However, these values are well below published values of US field studies.

In-situ measurements of overall duct leakage have been the subject of considerable research over the past ten years in single-family residential buildings (Cummings et al. 1990, Davis and Roberson 1993, Jump and Modera 1994, Jump et al. 1996, Modera 1993, Modera and Jump 1995, Parker et al. 1993, Proctor and Pernick 1992). The general consensus that evolves from these papers is that residential duct systems have considerable leakage (10-20\% of fan flow on each side of the fan), and that that leakage has important impacts on energy use and cooling capacity. Several field studies of duct leakage in small- or light-commercial buildings (generally less than $900 \mathrm{~m}^{2}\left(10,000 \mathrm{ft}^{2}\right)$ ) have been conducted in California and Florida (Cummings et al. 1996, Delp et al. 1998a, Delp et al. 1998b). Delp et al. (1998c) report total leakage classes on 33 smallcommercial buildings that range from 130 to $1300 \mathrm{cfm} @ 1$ " $\mathrm{H}_{2} \mathrm{O} / 100 \mathrm{ft}^{2}$, with a mean of $447 \mathrm{cfm} @ 1 " \mathrm{H}_{2} \mathrm{O} / 100 \mathrm{ft}^{2}$. Also, these field studies suggest that duct leakage in these buildings is actually higher than that found in residences, the average leakage in the supply ducts being about a quarter of fan flow.

Prior investigations on duct leakage in large commercial buildings in the US are very limited, although testing-and-balancing engineers have numerous anecdotal stories of high leakage rates in such buildings. The only work easily available is that of Fisk et al. 
(1998) who report ASHRAE leakage classes that range from 60 to $270 \mathrm{cfm} @ 1$ 1" $\mathrm{H}_{2} \mathrm{O}$ / $100 \mathrm{ft}^{2}$ in four ductwork sections of two large commercial buildings. Besides, detailed analyses based on numerical simulations suggest large energy implications of duct leakage for this type of buildings. Franconi et al. (1998) estimate that duct leakage results in an increase in annual fan energy consumption of about $55 \%$ based on simulations on a VAV system with a ducted supply and a ceiling-plenum return. Given that fans in large commercial buildings consume approximately $30 \mathrm{kWh} / \mathrm{m}^{2}$ per year $\left(3 \mathrm{kWh} / \mathrm{ft}^{2}\right)($ Modera et al., 1999), eliminating air leakage from large commercial duct systems would result in an electricity energy savings potential on the order of $10 \mathrm{kWh} / \mathrm{m}^{2}$ per year $\left(1 \mathrm{kWh} / \mathrm{ft}^{2}\right)$.

This paper reports on the application, in two large commercial buildings, of a new technology that simultaneously seals duct leaks and measures effective leakage area of ducts. The technology is based upon injecting a fog of aerosolized sealant particles into a pressurized duct system. In brief, this process involves blocking all of the intentional openings in a duct system (e.g., diffusers). Therefore, when the system is pressurized, the only place for the air carrying the aerosol particles to exit the system is through the leaks. The key to the technology is to keep the particles suspended within the airstream until they reach the leaks, and then to have them leave the airstream and deposit on the leak sites. The use of aerosol particles to seal ductwork from the inside was brought to the proof-of-concept stage in 1994 by researchers at Lawrence Berkeley National Laboratory (LBNL) (Modera and Carrié 1996, Carrié and Modera 1998). The technology has been applied in several thousand residential buildings, some of which have been reported on in the literature (Modera et al. 1996). Although leaks as wide as $1.6 \mathrm{~cm}$ (5/8 inch) can be sealed with this technique, it is recommended that leaks larger than about 6-7 $\mathrm{mm}(1 / 4$ inch) be sealed manually before aerosol sealing is performed.

Although aerosol duct-sealing has been successfully tested in natural ventilation shafts, it is not suitable for many other building cavities such as ceiling-plenum returns or HVAC rooms. When present, these cavities can account for a large portion of the total HVAC system leakage (Cummings and Withers 1998) and may have a significant impact on the system energy use. However, Franconi et al. (1998) have shown that sealing supply leaks 
in large commercial buildings that use the ceiling plenum as a return should result in significant energy savings.

The first aerosol-based ductwork sealing in a commercial building was completed in 1997, and was performed on a flexduct system connected to a rooftop HVAC packaged unit on a small office building. Although that sealing process proved to be very successful, sealing the ductwork in a large commercial building poses previously unaddressed challenges. Specifically, large commercial buildings contain duct systems that are larger in cross-section, and considerably longer. Also, large systems may incorporate equipment within the ductwork, including Variable-Air-Volume (VAV) flow control boxes, and turning vanes, which might be sensitive to aerosols.

The goals of our research are (1) to assess the applicability of sealing large duct systems with the aerosol-based sealing technology; and (2) to develop and test the required sealing equipment and protocols for this type of sealing. 


\section{Methodology}

Our methodology consisted of field testing of the sealing technology in two large commercial buildings, along with limited laboratory investigations of the impacts of aerosols on VAV performance and operation, and of various taping protocols used to temporarily seal off diffusers.

\section{Building selection}

We performed field tests on isolated sections of ductwork in two commercial buildings, both of which were constructed of rectangular sheetmetal ducts with external insulation. One was a Constant-Air-Volume (CAV) system, and the other was a Variable-Air-Volume (VAV) system with turning vanes and three VAV boxes. Both systems are shown schematically in Figure 1 and Figure 2, and some of their physical characteristics are summarized in Table 1

\section{Isolation of sections of ductwork}

In order to perform the sealing process and effective leakage area (ELA) measurement, the selected sections of ductwork had to be isolated from the building, as well as from other sections of the ductwork that might contain sensitive components (e.g., heating/cooling coils, fans, etc.). The isolation of the ducts from the conditioned portions of the building was accomplished using a combination of clear tapes designed to withstand the pressures generated by the aerosol sealing process. Although the tapes were found to withstand up to $400 \mathrm{~Pa}$ at room temperature during laboratory testing at LBNL, they showed some signs of failure at $200 \mathrm{~Pa}$ in Building LS-1 at the elevated temperatures associated with aerosol sealing. This resulted in the sealing process being stopped short of completion in Building LS-1. The combination of a different diffuser design and the use of more-adhesive tape allowed the sealing process to be brought to completion in Building LS-2 (see Figure 3). To protect other sections of the ductwork and building from aerosol exposure, barriers made of cardboard and polystyrene panels were taped in place across the duct section just upstream of the injection point. 


\section{Aerosol injection apparatus}

Aerosol injection was achieved using an apparatus that consists of (1) a fan capable of maintaining the proper airflow in the duct system; (2) several electric resistance heaters; (3) a counter-rotating-vortex atomization nozzle; (4) a high-pressure fan to drive the flow through the nozzle; and (5) a peristaltic pump to supply the liquid-suspended sealant material. The heaters, which provide a total of $6.6 \mathrm{~kW}$ of heating, serve to evaporate away the water in which the sealant material is suspended. The water is evaporated away so as to create solid sticky particles prior to the mist entering the duct system (suspension is $12 \%$ solids by weight). The fan in the injection apparatus is designed to maintain duct flow over the range of pressures created in the duct system during sealing. The objective is to maintain an air velocity on the order of $1 \mathrm{~m} / \mathrm{s}(3.3 \mathrm{ft} / \mathrm{s})$ in the main trunk ducts during the sealing process. The peristaltic pump maintains a steady flowrate of liquid through the nozzle.

We used a Mark V (University of Washington) cascade impactor with 10 stages to assess in the laboratory the particle size distribution generated by the atomization nozzle (Pilat et al. 1970). Approximately $80 \%$ of the mass of these particles have aerodynamic diameters larger than $5 \mu \mathrm{m}$.

\section{Effective Leakage Area measurement}

The Effective Leakage Area (ELA) at a reference pressure of $25 \mathrm{~Pa}$ is defined as the effective size of an orifice that would produce the same flow as the sum of the duct leaks at $25 \mathrm{~Pa}$. It is not the physical area of the hole, but rather the effective area (e.g., the ELA of a sharp-edged orifice is about 0.6 times its physical area). The ELA of both duct systems was measured before, after, and during sealing, using the same equipment employed to perform the sealing, which is connected to the duct system with a tube of clear $0.65 \mathrm{~m}$ (25.5 inch) diameter lay-flat polyethylene tubing (see Figure 4). The ELA before and after sealing was measured at $25 \mathrm{~Pa}\left(0.1\right.$ inches $\left.\mathrm{H}_{2} \mathrm{O}\right)$ duct pressure by means of an automated leakage test in which the computer adjusts the fan flow until the duct pressure is equal to $25 \mathrm{~Pa}$. 
The ELA of the duct system at $25 \mathrm{~Pa}$ was also measured continuously by the computer during the sealing process. This is accomplished by continuously monitoring the flow through the fan and the pressure in the duct system. The ELA at $25 \mathrm{~Pa}$ is obtained by extrapolating the measured flow down to a pressure of $25 \mathrm{~Pa}$, assuming a flow exponent of 0.6 .

As the ELA tests performed acquire data similar to that obtained according to the SMACNA HVAC Air Leakage Test Manual (SMACNA 1985), we can also calculate the leakage class of these duct systems using the SMACNA flow exponent of 0.65. The SMACNA leakage class is defined as the leakage flow in $\mathrm{cfm}$ per $100 \mathrm{ft}^{2}$ at a pressure differential of $1 " \mathrm{H}_{2} \mathrm{O}(250 \mathrm{~Pa})$. (Note that the leakage class has dimensions of cfm per $100 \mathrm{ft}^{2}$.)

\section{Aerosol concentration measurements}

We devised a simple method to measure the particle concentration in the air leaving the duct at several locations in the system. This method does not require expensive aerosol sampling devices and is fairly easy to use on site. The basic principle behind this technique is to capture on an impaction plate most of the injector-generated particles leaving the duct system at a particular location. This was accomplished by cutting $2.5 \mathrm{~cm}$ (1 inch) diameter holes in the sheetmetal duct wall and by installing plates perpendicular to the flow $3 \mathrm{~cm}$ (1.25 inches) from the holes (see Figure 5 and Figure 6). Based upon an analysis with standard impactor design equations (Marple and Willeke 1976), the cut-off diameter of the impaction plates at a duct static pressure of $250 \mathrm{~Pa}$ is about $5 \mu \mathrm{m}$. (The cut-off diameter decreases with the fourth root of the duct static pressure.) Therefore, approximately $80 \%$ of the mass of the injector-generated particles impact on the plate at a duct static pressure of $250 \mathrm{~Pa}$. The holes were made large enough to assure that they

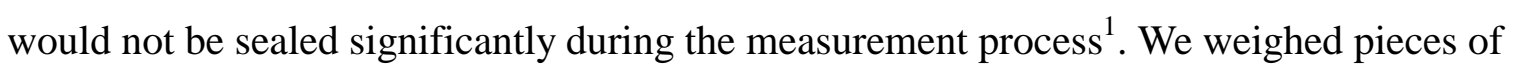

\footnotetext{
${ }^{1}$ In building LS-2, the 2.5 -cm holes were cut into separate metal plates that were used to cover larger holes cut into the duct system. The impact that particle deposition on the plate holes had on the flow through the holes was tested by measuring the change in flow through one of the plates after particles were deposited on it during sealing. The flow was found to decrease by less than $4 \%$ due to the particle deposition. Also, the degree of particle scrubbing at the hole was estimated by measuring the mass of particles deposited on
} 
paper clipped to the inside face of the impaction plates before and after being exposed to the exiting jet of aerosol particles. In addition, during each measurement period, the pressure differentials across the holes were monitored. These pressure differentials, along with orifice-flow equations for the holes, were used to determine the total volume of air leaving the holes during the measurement periods. The particle concentration leaving the duct system at a specific location is equal to the measured mass of material deposited on the paper divided by the total volume of air leaving the hole during that period.

\section{Aerosol deposition on duct walls}

Previous experience with sealing of residential duct systems has shown that there are large variations in sealing rates between different systems, and various possible explanations for those differences. Namely, particles removed from the airstream by gravitational settling and turbulent diffusion or particles that escape through the leaks are not available for sealing the leaks. For this reason, we devised some simplified means for evaluating the fate of the particles leaving the aerosol spray nozzle.

The first possible removal point for those particles is in the lay-flat plastic tubing used to connect the injection machine to the duct system. The losses on that tubing were measured in aggregate by weighing the tubing before and after the injection process.

The ratio of the particle mass concentration at some location in the duct system to the concentration entering the duct system decreases with distance from the injection point only because of particle deposition on the duct walls by gravitational settling and turbulent diffusion. Therefore, this ratio provides us with an indication of the extent of aerosol deposition on the duct walls. Note, however, that neither the penetration at a particular point in a duct system-i.e., the fraction of injected particles that are available for sealing downstream of that location-nor the fractional losses on the duct walls upstream of that location can be deducted from the concentration measurements only. To this end, airflow rate measurements would be necessary. However, these measurements 
are very difficult to perform on site, particularly in the transient conditions of the sealing process.

The average mass concentration of the aerosol leaving the duct system was measured at several locations using the impaction technique described above. The concentration entering the duct system was calculated from the ratio of the measured air and liquid flow rates through the injector, multiplied by the ratio of solids mass to total mass in the injected liquid (0.12), and the fraction of the solid that was not deposited on the lay-flat tubing.

\section{Register flow measurements}

One expected benefit of duct sealing lies in the potential reduction of the fan flow rate, which can result in substantial energy savings (Franconi et al. 1998). To quantify this effect, register flow measurements were performed before and after aerosol sealing in Building LS-2. This was achieved with an LBNL-designed active flow-hood described by Fisk et al. (1998). It basically consists of a collection hood connected in series with a variable-speed fan equipped with an integral flow meter. The fan speed was adjusted to maintain a zero static pressure difference between the interior of the collection hood and the room air. Therefore, the register flow rate should only be marginally affected by the presence of the device, the boundary conditions seen by the register being the same with and without the hood. With this device, we expect to measure the flows at the registers with an accuracy of $\pm 5 \%$.

To make relevant comparisons, we assured that the airflow measurements were performed at similar duct system operating conditions, i.e., the fan was turned to fullspeed and the VAV dampers were blocked in fully-open positions. 


\section{Results and Discussion}

\section{Measurement of Effective Leakage Areas}

The measured ELAs of the two duct systems before and after sealing are summarized in Table 2.

The profiles of measured ELA during the sealing process are presented in Figure 7. (These profiles are based on flows extrapolated using a flow exponent of 0.6 , which explains the discrepancies between the final ELAs shown in Figure 7 and the post-sealing ELAs calculated with the airflow rate measurement at $25 \mathrm{~Pa}$ reported in Table 2.) These data are similar to what is provided on a computer screen during the sealing process, the difference being the units and the combination of two sealing profiles in Figure 7.

It is clear from Figure 7 that the sealing process can be well documented by the hardware used to do the sealing. However, it is also clear that the sealing process was considerably more rapid in Building LS-1. There were a number of differences between the two buildings that could contribute to the observed difference in sealing rates. The two most obvious differences are that the system in Building LS-2 is both considerably larger and considerably tighter (in terms of ELA). Figure 7 shows that the sealing rates seem to be dropping off as the systems become sealed and that Building LS-1 has slightly higher sealing rates at the overlapping leakage levels for Buildings LS-1 and LS-2. Three possible explanations for the change in sealing rate with duct tightness are (1) that as the ELA is reduced the flow through the system is reduced according to the injector fan curve, with the lower flows for the tighter system resulting in less particle penetration; or (2) that the smaller leaks are sealed first, leaving the larger leaks with lower sealing efficiency to be sealed later in the process; or (3) that leaks close to the injection point are sealed first, which leaves leaks further from the injection point to be sealed, which are subjected to lower penetration rates. 


\section{Aerosol concentration measurements}

The depositional losses of particles on the lay-flat tubing and time periods for the impaction plate measurements are summarized in Table 3 The aerosol concentration ratios in the duct system from the impaction plates are presented as a function of distance from the injection point in Figure 8. The concentration ratios in Figure 8 are based on the concentration of particles entering the duct system (i.e., the losses to the lay-flat tubing are subtracted prior to calculating the ratio).

Table 3 shows that a significant fraction of sealant material is lost in the lay-flat tubing, and Figure 8 displays concentration ratios in the range of 10 to $50 \%$. These results suggest that there is significant deposition in the duct system prior to the sealant material reaching the leaks. Also, hypothesizing that leaks close to the injection point are sealed first to explain the lower sealing rates observed later in the sealing process (see Figure 7 ) is consistent with the significant decrease in the concentration ratios with distance from the injection point. On the other hand, Figure 8 suggests that, because the concentration ratios do not change significantly as the system is sealed, the decreasing sealing rates with duct tightness are probably not due to lower penetration rates.

\section{Aerosol particles in VAV units}

It is of course possible to isolate VAV boxes from aerosol particles by blocking off the box and injecting on either side. However, the sealing process would be simplified considerably if we are able to let aerosol particles pass through the VAV units; i.e., the leaks upstream and downstream of the units could be sealed simultaneously from the same injection point. For this reason, we injected aerosol-laden air through the three VAV boxes in Building LS-2. To test for potential detrimental effects of aerosol particle injection on the performance of the VAV terminal units, the flow calibration of one of the units in Building LS-2 was tested before and after the sealing process. (The pressure sensor tubes were pressurized with clean air during the sealing process.) The calibrations were performed by simultaneously measuring the velocities with a hot-wire anemometer on a grid within the duct just downstream of the VAV unit while measuring the pressure signal from the VAV flow sensor. A comparison of pre- and post-sealing VAV calibrations 
is presented in Figure 9, which suggests that the sealing process did not impact the flow

sensor on the WAV box. We also verified that the damper on the VAV unit operated properly after the sealing process.

A separate laboratory experiment was also performed to assess the influence of the aerosols on another VAV control unit. Its airflow sensor was calibrated in the laboratory. The unit was then installed in a laboratory duct system and subjected to aerosol sealant at an air velocity of $0.5 \mathrm{~m} / \mathrm{s}$ at the VAV inlet and a dry aerosol concentration of approximately $0.3 \mathrm{~g} / \mathrm{m}^{3}$, typical for a sealing operation. For the experiment, the VAV unit with its damper fully open was subjected to aerosol flow for two hours. The unit survived with no discernable ill effects; there was no change in its flow meter calibration, and damper function was normal.

Impact of duct leakage reduction on register flow rates

The measured register flow rates before and after sealing in Building LS-2 are displayed in Figure 10 It is noteworthy that the sealing had a very significant impact on the flow rates of some registers. The relative increase in airflow rate through individual registers ranges from about -5 to $+48 \%$; it is greater than $10 \%$ for three registers. The total airflow rate increased by $5.4 \%$. A statistical analysis was performed to derive the error bounds of the total airflow rate increase. The accuracy of the active flow-hood being $\pm 5 \%$ for each of the 18 individual measurements (registers 15 and 20 had no flow), the expected accuracy on the total airflow rate measurement can be estimated by $5 \% / \sqrt{18}=1.2 \%$. This error adds in quadrature as we look at the difference between pre- and post-sealing total airflow rate measurements. Therefore, the expected absolute error on the airflow rate increase is $\sqrt{2(1.2 \%)^{2}}=1.7 \%$. In sum, the total airflow rate increased by $5.4 \% \pm 1.7 \%$. 


\section{Conclusions}

Our aerosol sealing field trials in two large commercial buildings showed that $66 \%$ to $86 \%$ of the leakage in the duct systems could be sealed within several hours of aerosol injection, with no identified adverse impacts from the sealing process. These results suggest that with the commercially available sealing equipment that we used, we will often need to isolate sections of entire duct systems in order to seal them. New equipment and protocol developments (e.g., higher capacity injection units, or multiple injection units) could increase the size of duct sections that can be sealed.

One expected benefit of duct sealing lies in the potential reduction of the fan flow rate, which can result in substantial fan energy savings (Franconi et al. 1998; Modera et al. 1999). The fan energy consumption in large office buildings in the US is typically on the order of $30 \mathrm{kWh} / \mathrm{m}^{2}$ per year $\left(3 \mathrm{kWh} / \mathrm{ft}^{2}\right)$ (Modera et al. 1999). Besides, since the fan power is somewhere between a quadratic and cubic function of fan flow rate, achieving a change in the fan flow as low as 5\% would result in 10 to $15 \%$ savings on the fan energy use. This suggests energy savings on the order of 3 to $4.5 \mathrm{kWh} / \mathrm{m}^{2}$ per year assuming an airflow rate change of $5 \%$.

Despite the overall success of the sealing experiments, the aerosol concentration ratios from the two field trials indicate relatively low particle penetrations on the long duct runs, which clearly is increasing the time required for sealing. Some options under consideration to reduce sealing times are (a) producing smaller particles; (b) injecting at multiple locations along the length of the duct system; (c) using higher flow rates at a single point in the duct system; or (d) using air extraction at the end of the long duct runs to improve penetration. Implementation of one of these options may be necessary when larger and longer sections of ductwork are sealed.

Our measurement data leaves two possible explanations for the decreasing sealing rates over the course of the sealing process: (1) small leaks are sealed first, leaving larger leaks that seal less efficiently; (2) leaks close to the injection point are sealed first, which leaves 
leaks further from the injection point to be sealed, which are subjected to lower penetration rates.

The two field trials presented in this paper indicate that aerosolized sealant particles can be used to seal ducts in large commercial buildings, with the sealing taking place over periods of a few hours. Moreover, we conclude that it is possible to blow aerosol sealant through some VAV boxes without adverse impacts.

On the other hand, there is considerable room for improvement with respect to the sealing rates achievable with this technology, particularly considering the significant decrease in measured aerosol concentrations with distance from the injection point. Further research is needed to assure that aerosol sealing does not damage VAV control units, but the first results presented in this paper are very promising. Further engineering is also needed to develop a practical technique for sealing the diffuser grilles during the sealing process. Modeling is underway to quantify the energy savings available from sealing of different types of HVAC systems found in large commercial buildings (Franconi et al. 1998).

\section{References}

ASHRAE (1997). 1997 ASHRAE Handbook: Fundamentals, American Society of Heating, Refrigerating, and Air Conditioning Engineers, Inc., Atlanta.

Carrié, F. R. and Modera, M. P. (1998). Particle deposition in a two-dimensional slot from a transverse stream, Aerosol Science and Technology, 28(3): 235-246.

Cummings, J. B., Tooley, J. J., Jr., and Dunsmore, R. (1990). Impacts of duct leakage on infiltration rates, space conditioning energy use, and peak electrical demand in Florida homes, Proceedings of ACEEE Summer Study, Pacific Grove, California, August 1990. American Council for an Energy Efficient Economy, Washington, D.C.

Cummings, J. B., Withers, C. R., Moyer, N., Fairey, P., and McKendry, B. (1996)

Uncontrolled airflow in non-residential buildings, Florida Solar Energy Center, FSECCR-878-96. 
Cummings, J. B., and Withers, C. R. (1998). Building Cavities Used As Ducts: Air Leakage Characteristics and Impacts in Light Commercial Buildings. ASHRAE Trans. 104(II) 1998, pp. 743-752.

Davis, B. E. and Roberson, M. R. (1993). Using the "pressure pan" technique to prioritize duct sealing efforts: a study of 18 Arkansas homes. Energy and Buildings, 20(1): 57-63.

Delp, W. W., Matson, N. E., Tschudy, E., Modera, M. P., and Diamond, R. C. (1998a). Field investigation of duct system performance in California light commercial buildings. ASHRAE Trans. 104(II) 1998, TO-98-8-1.

Delp, W. W., Matson, N. E., Dickerhoff, D. J., and Modera, M. P. (1998b). Field investigation of duct system performance in California small commercial buildings (round II), Proc. ACEEE Summer Study 1998, pp. 3.105-3.116.

Delp, W. W., McWilliams, J., Dickerhoff, D. J., Wang, D., and Modera, M. P. (1998c). Thermal distribution losses in light-commercial buildings. What we know, and where we need to go from here. Lawrence Berkeley National Laboratory, LBNL-42415.

Fisk, W. J., Delp W. W., Diamond, R., Dickerhoff, D. J., Levinson, R., Modera, M. P., Nematollahi, M., Wang, D. (2000). Duct systems in large commercial buildings: physical characterization, air leakage, and heat conduction gains. Energy and Buildings, 32: 109119.

Franconi, E., Delp, W.W., and Modera, M. (1998). Impact of duct air-leakage on VAV system energy use, Lawrence Berkeley National Laboratory, LBNL-42417.

Hinds, W.C. (1982). Aerosol Technology: Properties, behavior, and measurement of airborne particles. John Wiley \& Sons. New York, USA.

Jump, D. A., and M. P. Modera. 1994. Impacts of Attic Duct Retrofits in Sacramento Houses. Proceedings of the 1994 ACEEE Summer Study on Energy Efficiency in Buildings, 9:195-203. Washington D. C.; American Council for an Energy Efficient Economy. 
Jump, D. A., I. S. Walker, and M. P. Modera. 1996. Field Measurements of Efficiency and Duct Retrofit Effectiveness in Residential Forced Air Distribution Systems. Proceedings of the 1996 ACEEE Summer Study on Energy Efficiency in Buildings, 1: 147-155.

Washington D. C.; American Council for an Energy Efficient Economy.

Marple, V.A., and Willeke K. (1976). Impactor design. Atmospheric Environment, 10: 981-896.

Modera, M. P. (1993). Characterizing the performance of residential air distribution systems, Energy and Buildings, 20(1): 65-75. Lawrence Berkeley National Laboratory, LBL-32532.

Modera, M. P., and Jump, D. A. (1995). Field Measurements of the Interactions Between Heat Pumps and Duct Systems in Residential Buildings. In Proceedings of ASME International Solar Energy Conference, March, 1995. Lawrence Berkeley Laboratory, LBL-36047.

Modera, M. P., Xu, T., Feustel, H., Matson, N., Huizenga, C., Bauman, F., Arens, E., and Borgers, T. (1999). "Efficient Thermal Energy Distribution in Commercial Buildings". Final report to California Institute of Energy Efficiency. Lawrence Berkeley National Laboratory, LBNL-41365.

Modera, M. P. and Carrié, F. R. (1996). Method and device for producing and delivering an aerosol for remote sealing and coating, The Regents, University of California. USA, US Patent $N^{\circ}$ 5,522,930. Jun. 4, 1996.

Modera, M. P., Dickerhoff, D. J., Nilssen, O., Duquette, H., and Geyselaers, J. Residential Field Testing of an Aerosol-Based Technology for Sealing Ductwork. Proceedings of ACEEE Summer Study, Pacific Grove, CA, August 1996, Lawrence Berkeley Laboratory Report, LBL-38554.

Parker, D., Fairey, P., and Gu, L. (1993). Simulation of the effects of duct leakage and heat transfer on residential space-cooling energy use, Energy and Buildings 20(2): 7-114. 
Pilat, M., Ensor, D. S., and Bosh, J. C. (1970). Source Test Cascade Impactor, Atmospheric Environment, 4: 671-679.

Proctor, J. P., and Pernick, R. K. (1992). Getting it right the second time: measured savings and peak reduction from duct and appliance repairs, Proceedings of ACEEE Summer Study, Pacific Grove, California, August 1992. American Council for an Energy Efficient Economy, Washington, D.C.

SMACNA (1985). HVAC Air Duct Leakage Test Manual, Sheet Metal and Air Conditioning Contractors National Association, Inc. Chantilly, Virginia.

Swim, W. B., and Griggs, E. I. (1995). Duct leakage measurement and analysis. ASHRAE Trans. 101(I), pp. 274-291. 


\begin{tabular}{|l|l|l|l|l|l|c|}
\hline $\begin{array}{c}\text { Building } \\
\text { ID \# }\end{array}$ & Age & $\begin{array}{c}\text { Floor Area } \\
\text { Served by Sealed } \\
\text { Section } \\
{\left[\mathbf{m}^{2}\left(\mathbf{f t}^{\mathbf{2}}\right)\right]}\end{array}$ & $\begin{array}{c}\text { Duct Surface } \\
\text { Area } \\
{[\mathbf{y r} .]}\end{array}$ & $\begin{array}{c}\text { Duct Surface } \\
\text { Area /Floor } \\
\text { Area } \\
\left.\left.\mathbf{m}^{\mathbf{2}} \mathbf{f t}^{\mathbf{2}}\right)\right]\end{array}$ & $\begin{array}{c}\text { Number of } \\
\text { Diffusers }\end{array}$ & $\begin{array}{c}\text { Nominal } \\
\text { Pre-Sealing } \\
\text { Air Flow } \\
{[\mathbf{L} / \mathbf{s}(\mathbf{c f m})]}\end{array}$ \\
\hline LS-1 & 39 & $220(2400)$ & $80(840)$ & $35 \%$ & 15 & $750(1600)$ \\
\hline LS-2 & N/A & $470(5000)$ & $180(1900)$ & $37 \%$ & 20 & $1890(4000)$ \\
\hline
\end{tabular}

Table 1. Building and duct-system characteristics 


\begin{tabular}{|c|c|c|c|c|c|c|}
\hline Building & $\begin{array}{c}\text { Pre-Sealing } \\
\text { Duct Leakage } \\
\text { ELA at } 25 \text { Pa } \\
{\left[\mathrm{cm}^{2}\left(\text { in }^{2}\right)\right]}\end{array}$ & $\begin{array}{c}\text { Pre-Sealing } \\
\text { Leakage } \\
\text { Class } \\
{[\mathrm{cfm} @ 1 "} \\
\left.\mathrm{H}_{2} \mathrm{O} / \mathbf{1 0 0} \mathrm{ft}^{2}\right]\end{array}$ & $\begin{array}{c}\text { Post-Sealing } \\
\text { Duct Leakage } \\
\text { ELA at } 25 \text { Pa } \\
{\left[\mathrm{cm}^{2}\left(\mathrm{in}^{2}\right)\right]}\end{array}$ & $\begin{array}{c}\text { Post-Sealing } \\
\text { Leakage } \\
\text { Class } \\
{[\mathrm{cfm} @ 1 "} \\
\left.\mathrm{H}_{2} \mathrm{O} / \mathbf{1 0 0} \mathrm{ft}^{2}\right]\end{array}$ & $\begin{array}{c}\text { Percentage } \\
\text { Reduction } \\
\text { in Leakage } \\
{[\%]}\end{array}$ & $\begin{array}{c}\text { Duration of } \\
\text { Aerosol } \\
\text { Injection } \\
{[\mathrm{h}]}\end{array}$ \\
\hline LS-1 & $320(50)$ & 230 & 110 (17) & 80 & 66 & 2.5 \\
\hline LS-2 & $190(29)$ & 60 & $24(4)$ & 8 & 86 & 5 \\
\hline
\end{tabular}

Table 2. Duct-system leakage results 


\begin{tabular}{|l|l|l|l|l|l|l|}
\hline Building & $\begin{array}{c}\text { Total Solid } \\
\text { Material } \\
\text { Injected } \\
{[\mathbf{g m}(\mathbf{o z})]}\end{array}$ & $\begin{array}{c}\text { Fractional } \\
\text { Loss on Lay- } \\
\text { flat Tubing } \\
{[\%]}\end{array}$ & $\begin{array}{c}\text { Time } \\
\text { Period for } \\
\text { Test 1 } \\
{[\mathbf{m i n}]}\end{array}$ & $\begin{array}{c}\text { Time } \\
\text { Period for } \\
\text { Test 2 } \\
{[\mathbf{m i n}]}\end{array}$ & $\begin{array}{c}\text { Time } \\
\text { Period for } \\
\text { Test 3 } \\
{[\mathbf{m i n}]}\end{array}$ & $\begin{array}{c}\text { Time } \\
\text { Period for } \\
\text { Test 4 } \\
{[\mathbf{m i n}]}\end{array}$ \\
\hline LS-1 & $670(23)$ & $33 \%$ & $2-16$ & $17-57$ & $58-139$ & N/A \\
\hline LS-2 & $1350(47)$ & $39 \%$ & $12-32$ & $55-71$ & $119-136$ & $179-197$ \\
\hline
\end{tabular}

Table 3. Lay-flat tubing deposition results and time periods for impaction plate measurements 


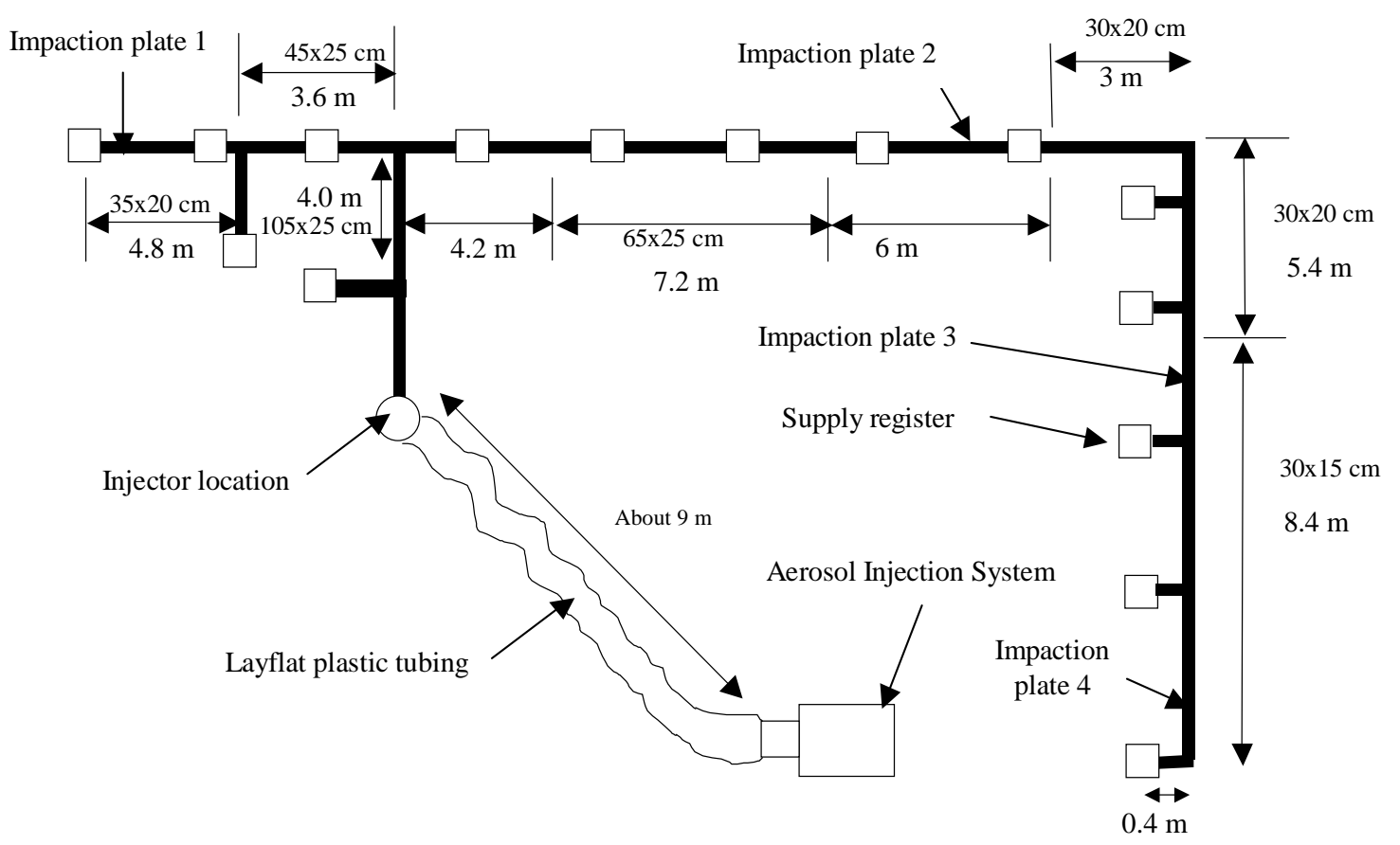

Figure 1. Duct layout and aerosol injector installation in Building LS-1 


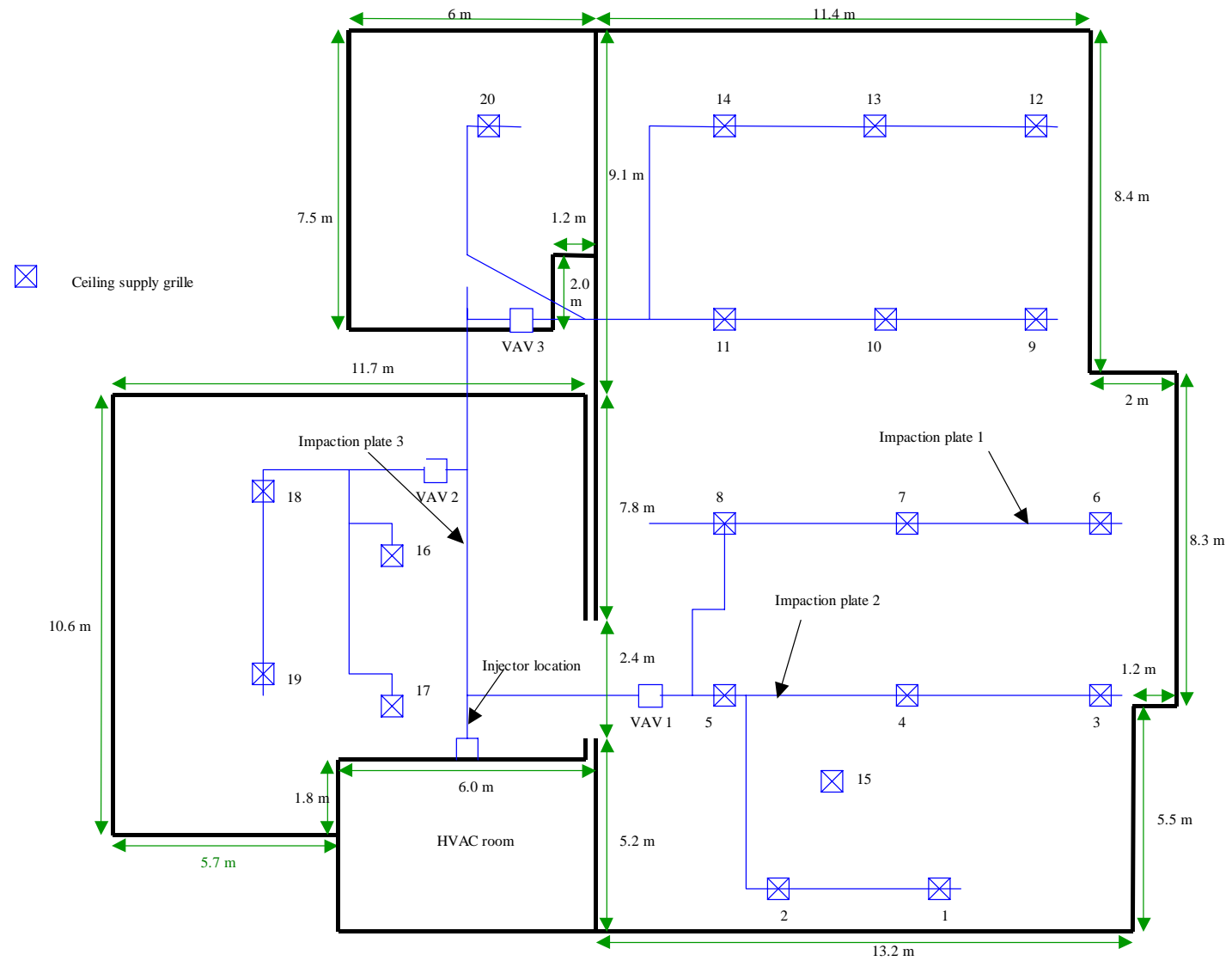

Figure 2. Duct layout and aerosol injector installation in Building LS-2. Supply diffuser 15 was not connected. 


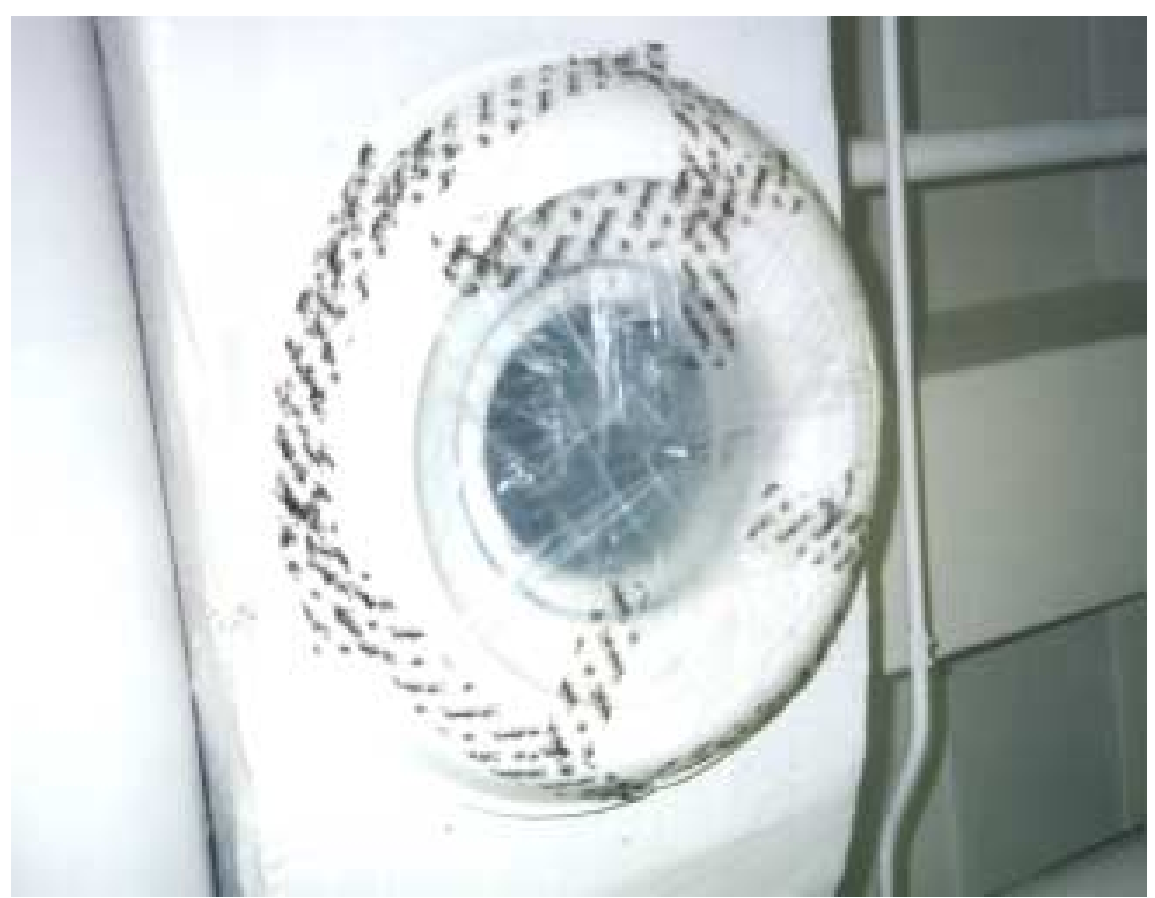

Figure 3. Sealed diffuser in Building LS-2 


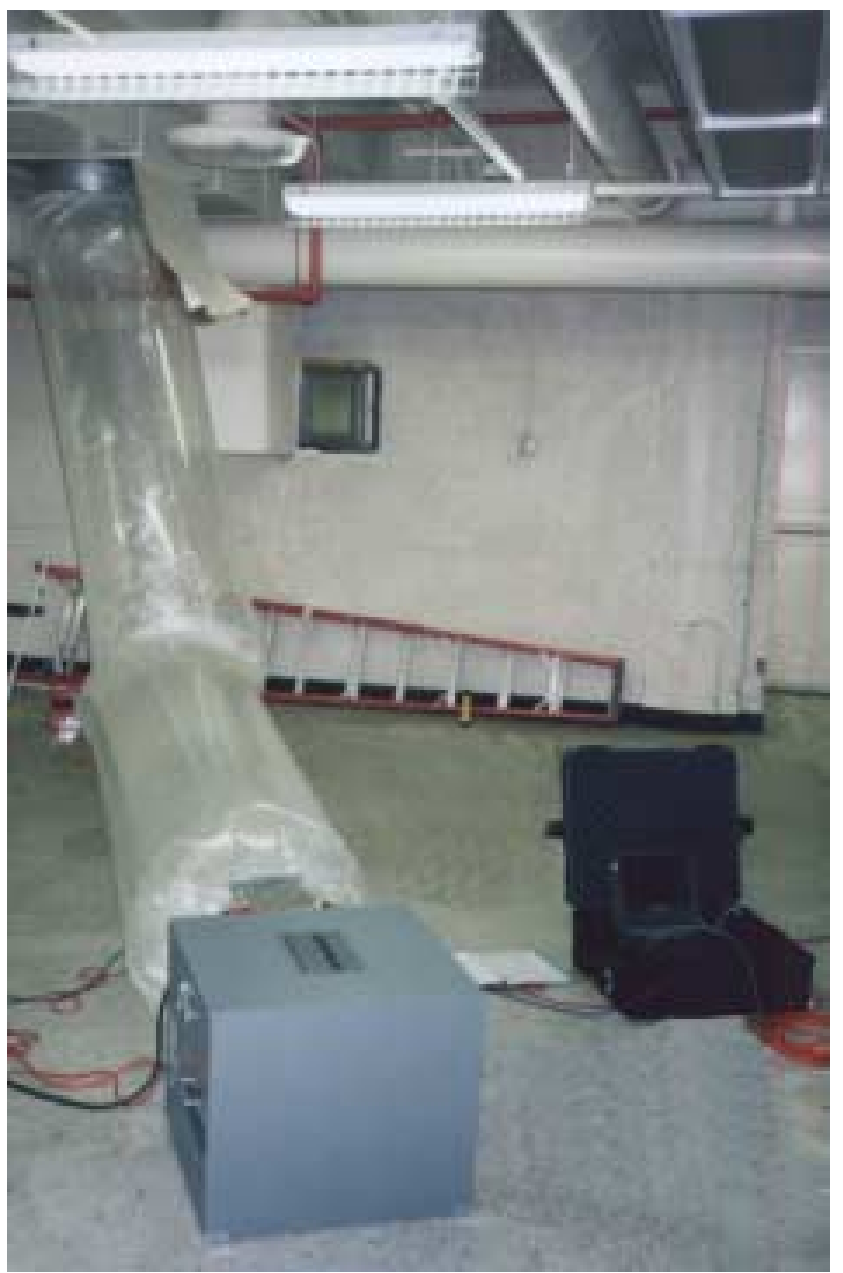

Figure 4. Aerosol injection machine connected to Building LS-2 via $0.65 \mathrm{~m}$ ( 25.5 inch) diameter layflat polyethylene tubing 


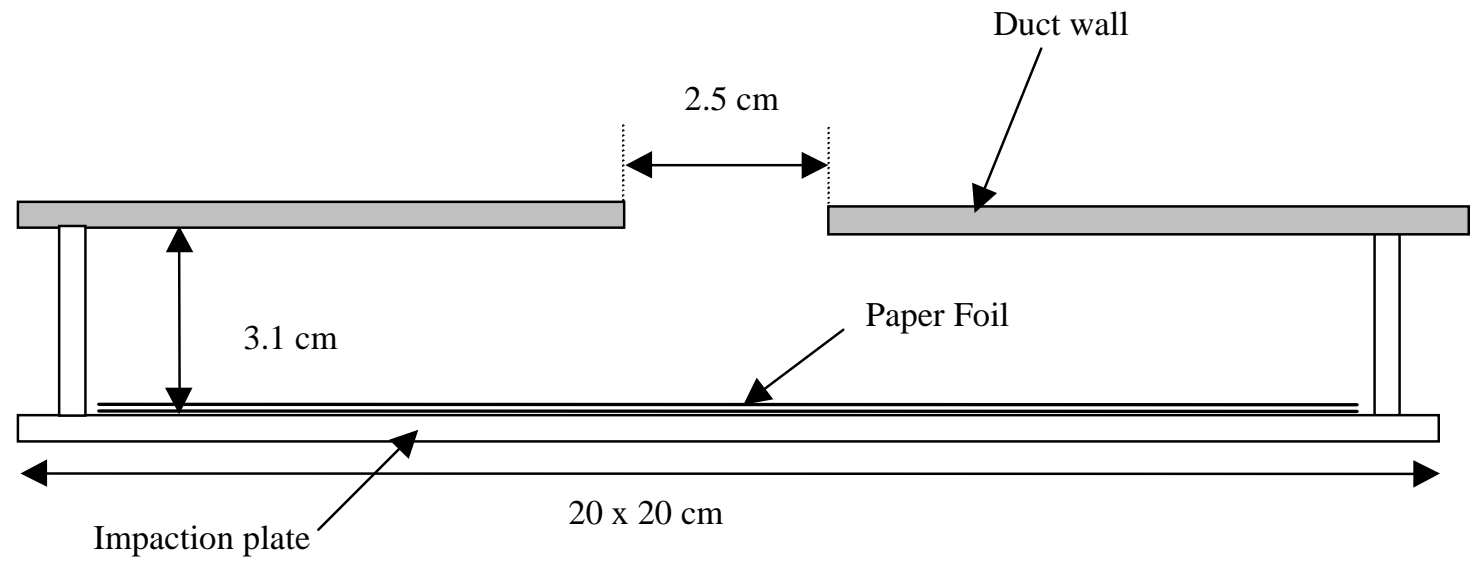

Figure 5. Schematic of impaction plate used to measure particle concentration 


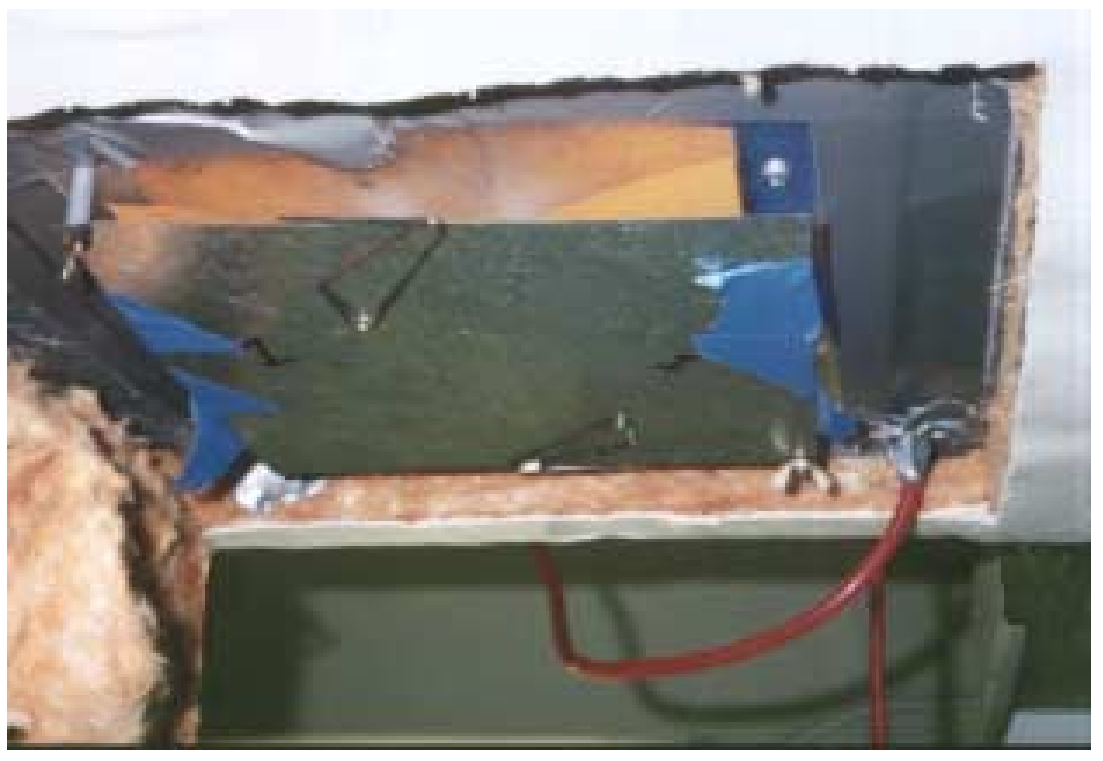

Figure 6. Impaction plate installed in Building LS-2 


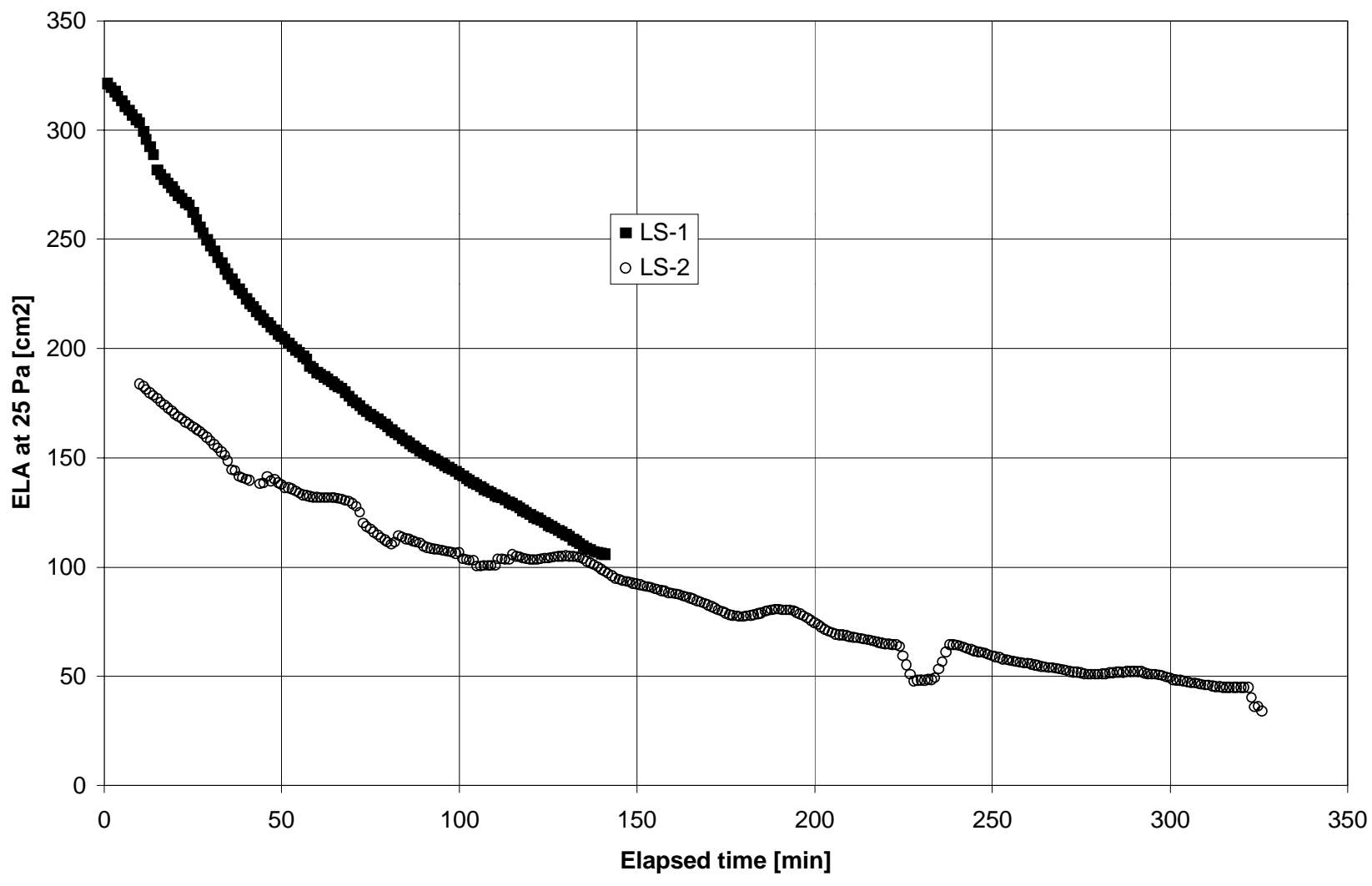

Figure 7. Time series profiles of effective leakage area during the sealing process in Buildings LS-1 and LS-2. For clarity, time periods during which there was no particle injection have been removed. 


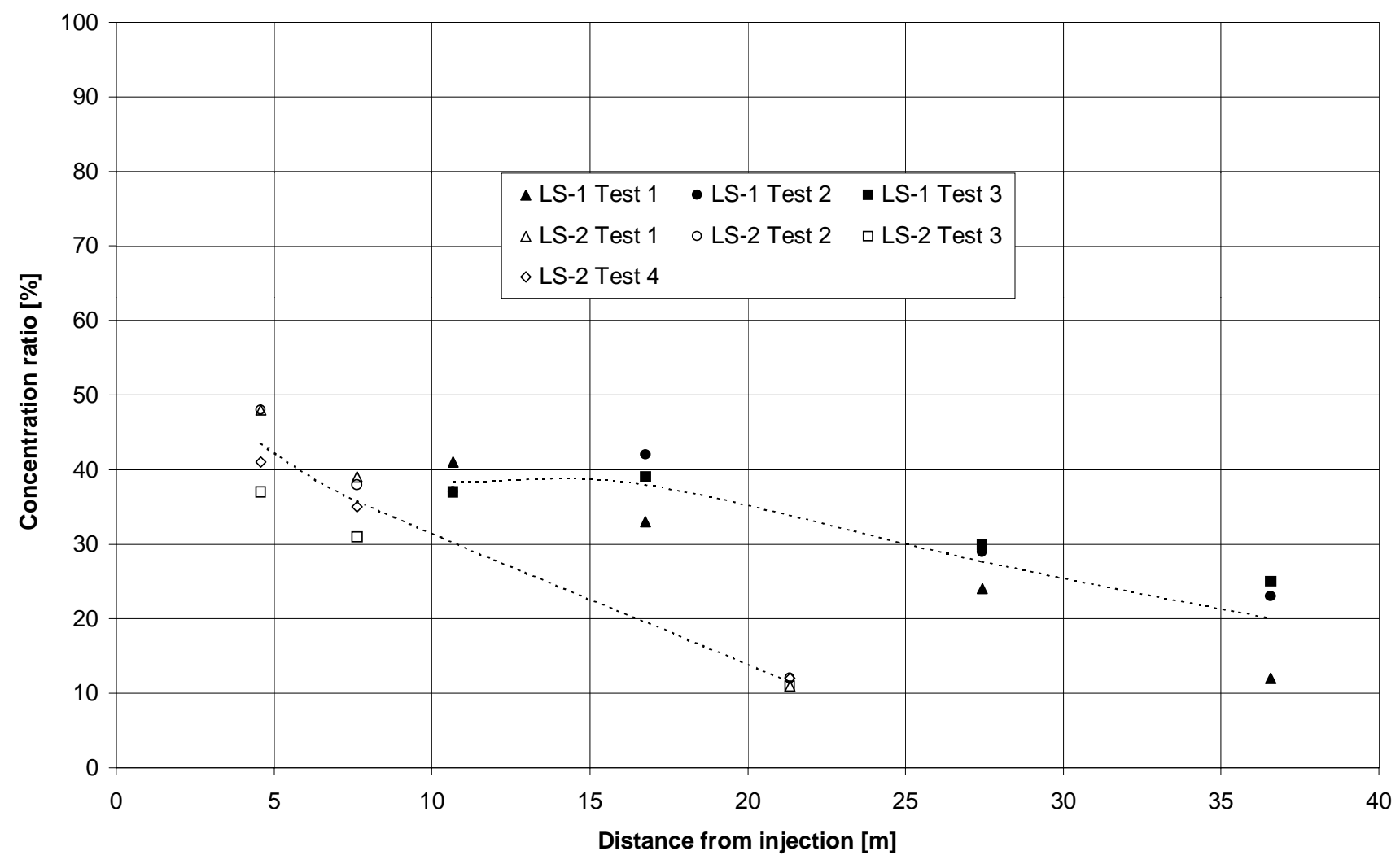

Figure 8. Concentration ratio of aerosol sealant as a function of distance from the aerosol injection point for Buildings LS-1 and LS-2. Impaction plate locations are shown in Figure 1 and Figure 2. Test periods are shown in Table 3 The dotted lines join the average concentration ratios at each location for building LS-1 and LS-2. 


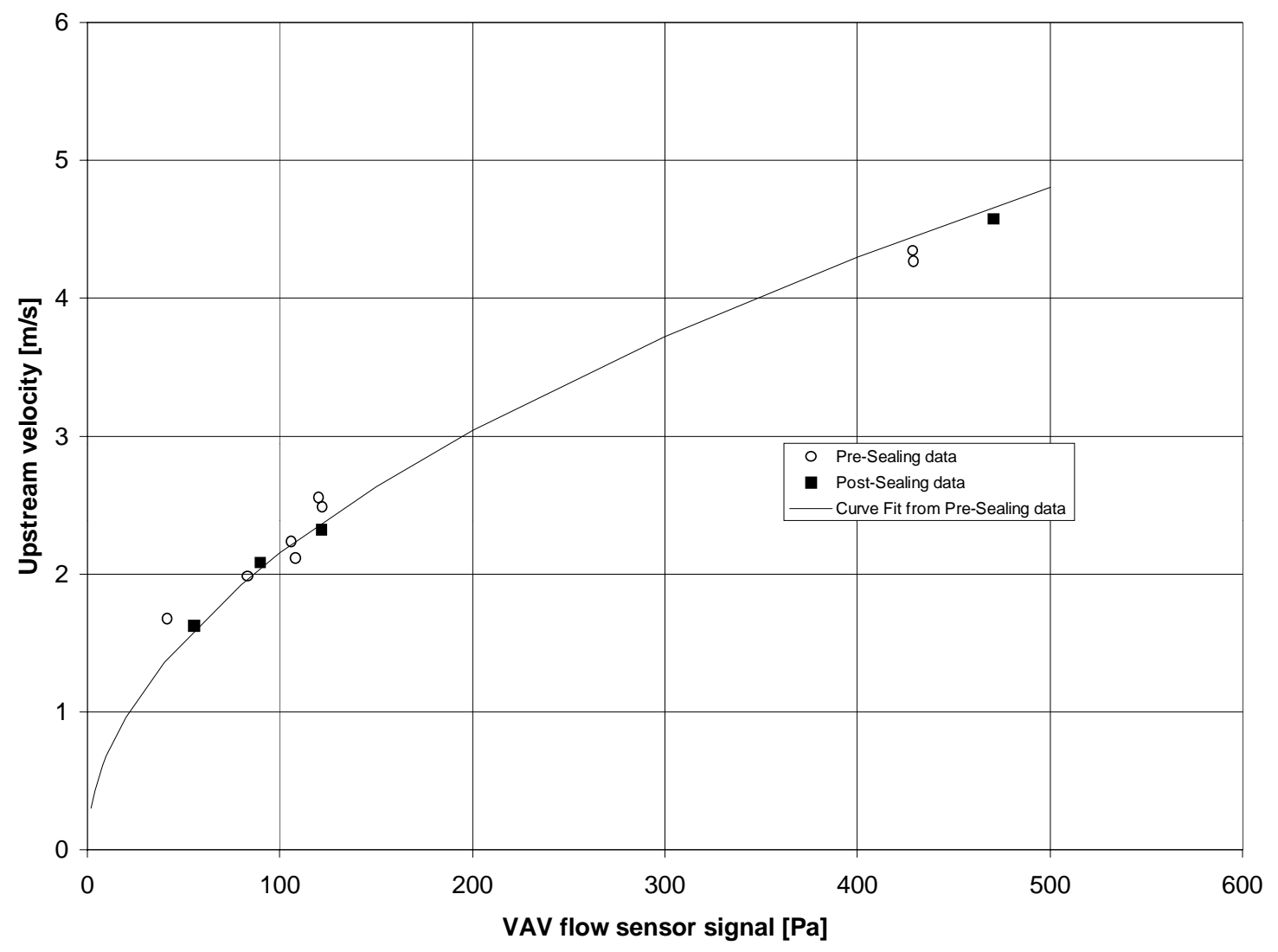

Figure 9. Comparison of pre- and post-sealing calibrations of VAV box in Building LS-2 


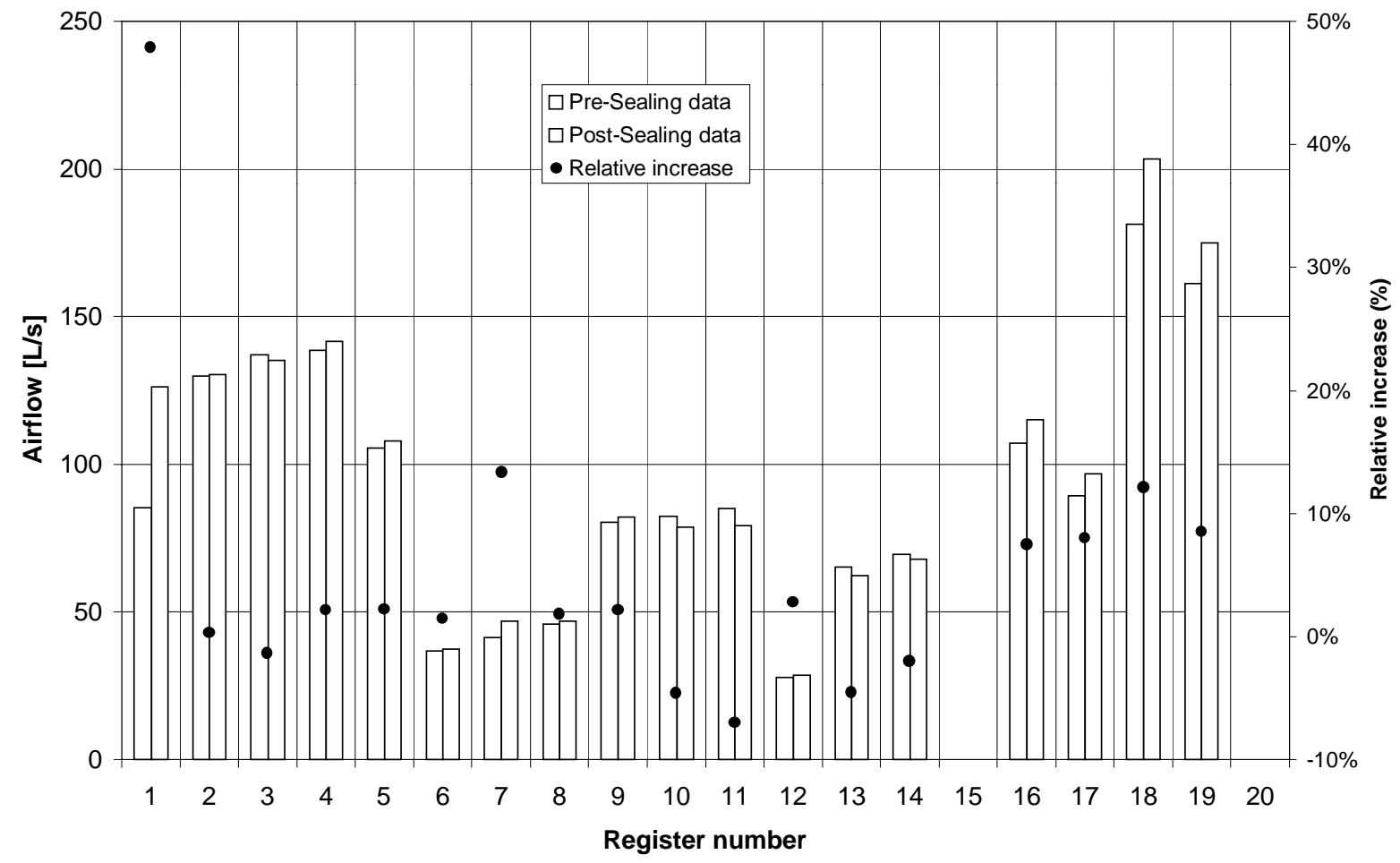

Figure 10. Pre- and post-sealing airflow measurements at the registers in Building LS-2. 